\title{
The Graduate Student's Use of the Subject Catalog
}

$\mathrm{T}$ HE CRITICISM is frequently heard that catalogers tend to think of cataloging as an end in itself, considering the description of the library's materials rather than the use which will ultimately be made of that description. In other words, the cataloger's chief concern has been with the book, not the reader.

This criticism is, to some extent, justified. However, the difficulty lies, not so much in the failure to consider the use which is to be made of the catalog or in a lack of appreciation of the significance of this factor of use by those who make the catalog, but rather in the insufficiency of knowledge regarding the reader and his approach to the catalog. If, for example, standardization in subject cataloging has gone too far, as has been suggested, the catalog can only be modified to suit the individual library's needs when knowledge of those needs is made specific and objective. It is not possible to fashion catalogs to meet the needs of the library's patrons unless more is known about the nature of these needs.

It was with this general problem in mind that the present study was undertaken. 'Specifically, the object of this investigation was to learn something about the use made of the subject catalog by a group of graduate students in a large university. These students were interviewed while they worked at the subject catalog in the preparation of their term papers.

1 Based on a master's thesis prepared at the Graduate Library School, University of Chicago, 1946.
Since the students in the social sciences might reasonably be expected to make greater use of the subject catalog than those in the humanities or sciences, two classes in sociology were selected for study. With few exceptions, the students in these classes were studying for advanced degrees, either M.A. or Ph.D.

The total enrolment of these two classes was about 160. However, only 33 , or slightly more than 20 per cent, could be persuaded to take part in this investigation. Many factors probably contributed to the meager response elicited from the students. Undoubtedly, the most important was a general lack of interest on the part of the students. In a busy academic schedule any attempt to impose further duties meets with considerable resistance. In a program already burdened with requirements a "suggested activity," like "suggested reading," tends to be ignored.

There are other factors present in the situation, however, which may be of some significance when considering the study as a whole. The students understood that the investigator was interested in knowing how the catalog helped or failed to help them when they were collecting material for their term papers. If they relied exclusively on sources other than the catalog for this material, they naturally would not see any occasion for reporting their methodology. Several students acknoweledged this during their interviews.

Similarly, a lack of familiarity with the 
catalog or an inability to use it with any success may have influenced some students against participation in the study through unwillingness to display their ineptitude. Barring those few of a genuinely uncooperative nature, it might not be unfair to assume that, of the 80 per cent who did not participate in the investigation, a large number made no great use of the subject catalog or else felt unable to use it intelligently, circumstances which possibly reflect aspects of the same problem rather than two different problems.

The interviews were all conducted at the catalog and varied from ten minutes to a half hour in length. The student stated briefly the general topic of his paper and explained in some detail his procedure in searching for material prior to consulting the card catalog. If he had used the catalog before coming for the interview, he reviewed each step of his search, indicating at the same time his success or failure in each case. Usually, however, the student and investigator went to the catalog together and the investigator had an opportunity to observe firsthand the student's use of the cata$\log$.

Those aspects of the student's use of the subject catalog which were of particular interest in this investigation should be mentioned here. First, a study was made of the terms in which the student expected a given idea to be expressed as a subject in the catalog. Equally significant is the order in which he looked for these terms. The trial-and-error method, which is used by those with enough patience to pursue this policy, is more revealing when the "trials" can be studied in sequence. Does the student go first to the general term or does he begin with a highly specific concept? What is the source of the term he selects? Does "he think, as a librarian does, of a "specific entry"? How does he interpret subdivisions of a subject and how does he use them? The student's understanding of the significance of a subject entry as opposed to a title or author entry was another question posed by the investigator. Answers to all these questions were found in no one case, but as each student was interviewed it was the answers to these questions which were sought.

Besides noting the subjects the student used and the pertinence of these subjects to his topic, an attempt was made to learn what factors contributed to the student's selection of titles under a given subject. If the student consults a subject like "Sociology" in the catalog and finds two drawers of cards when he requires only a few books, there is evident need for selection, since it is obviously impossible for him to examine the actual books represented by several thousands of cards. If the student is not so discouraged by the wealth of material under this subject that he gives up the search altogether, he will be obliged to make a choice of titles. The determining factors in this choice are of importance to those who are making and arranging the catalog he is to use.

A further point of interest concerned the use of the subject catalog as a supplement to other approaches which the student might have made to the material, since the subject catalog is only one means of finding information on a given subject. What other sources were consulted and which proved most useful? The answer to this question has implications for all librarians but particularly for those who make the subject catalog.

\section{Reports of Individual Students}

Two reports, selected from the thirtythree cases studied, are included here as examples of the type of information obtained from the interviews with the students. 
Case 4. "Rural recreation" was the topic chosen for this student's term paper. She was unfamiliar with any authors in the field and sought material of a general nature. She first looked up the subject "Recreation," considering only those books with imprint date later than I935. The wording of the title, together with the date, determined whether or not she would examine the book.

Next the student went in search of any subject which began with the word "rural." Here several titles relative to the subject were found. The student was highly pleased with this development, but was quite unaware that these were title entries. She considered them subjects like "Recreation" and consequently was disappointed that the library had only one book on "rural and small community recreation" and only two books on "rural community organization."

In considering the entries beginning with the word "rural," the student found "Rural Sociology" which, in turn, directed her to "Sociology, Rural." This subject suggested several books which were helpful.

The subjects "Village" and "Town" were next searched for in the catalog. The plural of the first term was found and material located which was pertinent to the topic in hand. A cross reference from "Town" led her to "Cities and Towns," a subject which proved too broad in scope to be useful.

This student read only English.

Case 32. The topic for the student's term paper was described as "race relations and housing." "Housing" was the first subject explored, and here the number of cards so discouraged the student that the subject received only a superficial examination. $\mathrm{He}$ decided that some other subject-perhaps he meant a more limited subject-would supply him with what he wanted. It might be mentioned that from the moment he approached the catalog he had a definitely defeatist attitude: "I never have found anything in the catalog; it's unlikely I will today."

$\mathrm{He}$ next looked for the subject "Race Relations" and found a cross reference under "Race Question" to "Race Problems." The reference suggested also the subdivisions "Nationality" and "Race Question" under names of countries, e. g., "U.S.Race Question." The student read only the "see" reference, however, and ignored the "see also" reference. This was unfortunate because books which appeared to treat of the problem of segregation were found by the investigator under "U.S.-Race Question," while the general subject "Race Problems" yielded less that was helpful.

"Negro," the subject he next tried, led him to "Negroes," and he selected a title from those listed under "Negroes-Civil Rights."

As a last resort, he turned to the subject "Prejudice" where he found a cross reference to "Antipathies and Prejudices." The books suggested there did not deal directly with his problem.

The student said he customarily sought the professor's advice regarding his selection of books on a given subject and preferred, when possible, to work through bibliographies rather than the subject catalog.

\section{Summary of Findings}

In reviewing the use which thirty-three graduate students made of the subject cata$\log$, the most obvious fact to be noted is that the subject catalog, for these students, was an unsatisfactory and inefficient instrument. In almost every case the student preferred to consult the professor's suggested reading list or to select titles from those listed in bibliographies which accompanied journal articles and chapters of books. Some students went directly to the 
professor for recommendations; others found the various indexes to periodicals more helpful than the subject catalog. But in every case the subject catalog was a "supplementary tool." Even those students who were accustomed to using the catalog and said they experienced little difficulty finding material, seldom searched the subject catalog before consulting reading lists and bibliographies.

These graduate students were not writing term papers for the first time. Nor were they meeting the subject catalog for the first time. Their use of the subject catalog was conditioned, to some extent, by the success or failure which they had experienced in the past when they had consulted the catalog and, in some cases, that past experience had not been such as to encourage them to rely on the catalog for help in finding material on a given subject.

The important question to consider is: Why was it that the students found the subject catalog unsatisfactory for their purposes? Was the difficulty inherent in the design of the catalog itself or did the limitations lie with the student and his methods of using the catalog? A categorical answer cannot be admitted. Both those who made the catalog and those who used it were responsible in part for the difficulties which the students experienced.

The inadequacies of the catalog itself, with reference to the particular cases studied, are fairly obvious. It has been charged that the subject catalog is of little use to the specialist except on those occasions when he is not specializing. For example, the biologist, when making a study of the utilization of salt in the human body, would not use the subject catalog as an aid in his search for secondary material. If this same biologist wanted a book on the Civil War in Spain he might very conceivably rely on the subject catalog to locate such a volume. These thirty-three graduate students whose methods of research were studied were likewise specialists working in their own field. With one or two exceptions, they were all concentrating in the division of the social sciences and most of them expected to study for degrees in the department of sociology. Some of them were already launched on Ph.D. theses. The standard works in sociology were familiar to them, and the bibliographies and references in these volumes often served as a point of departure for a study of their individual topics. The reading list for this course, together with those distributed in previous courses taken in the department, provided selected bibliographies from which the student could choose titles relevant to his topic.

\section{Periodical Indexes More Popular}

This topic, it should be remembered, was for a term paper, not an exhaustive treatise. It is not usually necessary, in preparing a term paper, to examine all the material on the subject. This accounts for the fact that a good many of the students were content with $a$ book, requiring neither all the books nor even all the best books. The topic of a term paper should be one that can be discussed to some purpose in three or four thousand words. Consequently, some of the topics chosen by the students were more likely to be the subjects of articles in journals or chapters in books. The subjects in the catalog are, on the whole, subjects of books. The material which they sought might be expected to be brought out by a subject entry for an analytic, less frequently by a subject entry for a book. In view of this fact, it is not surprising that the periodical indexes proved so popular.

Still another characteristic of the topics which the students selected to discuss made it more likely that the information would 
be found in journals. Some of the students were exploring in areas where little had been written. In some instances, they expected to incorporate this paper into a larger master's or doctoral thesis. They were working on the fringe of a body of knowledge, and the subject had not developed far enough to be included in very many books, although it might be of sufficient interest to be the topic of a journal article.

Similarly, the topical character of a subject like race relations and housing makes it unlikely that this subject would be found widely discussed in books, although the problems of segregation and restrictive covenants are being widely discussed today.

It is apparent that the nature of the cata$\log$ and the kind of material it indexes is, to some extent, responsible for the dissatisfaction which the students experienced. When the student wanted a selected list of the best books on a subject, the catalog was unselective. All titles in the catalog received the same subject treatment, and no attempt was made to evaluate individual books. On the other hand, when the student wished an unselected list, as he did when he asked for all the material in print on a given subject, the catalog presented him with a selected list, selected in the sense that only those volumes in the library were given subject headings in the catalog.

Aside from these limitations inherent in the catalog itself, the students experienced difficulties directly traceable to their own inexperience and lack of skill in using the catalog.

An example of a difficulty of this kind can be seen in the students' inability to distinguish between a title entry and a subject entry. Perhaps it would be more nearly correct to speak of their ignorance regarding the whole concept of entry. It was obvious in more than a few cases that the student was unaware that a book was en- tered in the catalog under the author, subject, title, etc. It did not occur to him that those entries in capital letters or in red ink were a different kind of entry from those in small letters. The title entry, when used intelligently, can be very helpful as a substitute for a subject heading or as a cross reference, through the Library of Congress suggestions for subject headings, to other material on the same subject. But when the title entry is not interpreted for what it is, the student may be misled into believing that he has found all the material the library has on the subject. For example, both the student who looked up "rural recreation" and the student who found four title entries beginning with the words "race relations" thought that they had exhausted the library's resources in these areas.

\section{Specific Entry Concept}

An idea clearly as foreign to the student mind as that of title entry is the concept which the librarian refers to as "specific entry." In many instances the student was unconsciously applying this idea up to a certain point. He consulted a specific entry in his initial search for material. However, if he failed to find as many titles as he had hoped or if those he did find were unsatisfactory for some reason or other, he would examine broader subjects but still with the expectation of finding the specific information he was seeking. In one instance, the student, after consulting "Moving Pictures-Moral and Religious Aspects," turned for additional information on the same topic to the subjects "Pathology, Social Disorganization" and "Social Psychology." The students expected to find material on a limited subject under both the specific and broad heading.

The student was further hampered in his use of the catalog because he failed to notice the various devices which might have 
served to refer him from the subject he was consulting to other allied subjects. "See" references he understood; "see also" references he was less likely to utilize to their fullest extent. In only one case had the student observed that the Library of Congress suggestions for subject headings could lead him to other subjects closely related to the one he was considering. Except for the simple cross references, the suggestions which the catalog itself could have furnished went unnoticed in the majority of cases. The student simply consulted the subjects in succession as they occurred to him.

In considering what term or terms they would look for in the catalog, some of the students were handicapped by being relatively unfamiliar with the subject. Consequently, it was difficult for them to give a name to the idea which they wished to discuss. One student said that when the subject in which he was interested was a very specific one, he did not know what term to consult in the catalog; when the subject was a general one, he was confused by the number of titles listed under it.

Impatience characterized many of the students' searches through the subject cata$\log$. If the first trial did not lead them to what they wanted, they were tempted to give up the search. If they found a great many titles listed under a subject, they were almost as discouraged as when they found none. The search through a wealth of material under a broad subject could have been less burdensome had the students considered the various subdivisions under one general subject as representing concepts which were, on the whole, mutually exclusive. Generally, however, the students examined each title under the broad heading, considering the subdivisions only as guides to the aspect of the subject which was treated in a given book. In other words, the students first looked at the title and then used the subject subdivision as a guide to content or treatment rather than consulting the various headings and then selecting the titles under the most appropriate subdivisions of the subject.

\section{Basis for Selection of Titles}

As has been mentioned earlier, an attempt was made not only to learn how the students approached the subjects they did but also on what basis they made their selection of titles under a given subject. The language in which a book was written appeared to be the chief consideration when a student was choosing a few titles among the many suggested under a subject. The field of sociology leans heavily on source materials available only in German, but these embryo sociologists, with few exceptions, did not read German. Sometimes as many as 50 per cent of the titles listed under a subject which a student examined in the cata$\log$ represented books in a language other than English. Rarely did a student have a knowledge of a foreign language which permitted him to consult books written in that language, even though the information was unavailable in English. Strangely enough, this language factor operated almost unconsciously sometimes, the student seemingly being unaware that many of his most valuable sources were unavailable to him because he was compelled to eliminate from his consideration any material not in English. Other students, particularly those who were studying the works of one man, regretted the inadequacies of the translations available.

Among the English titles the student generally selected those which, to judge by the phraseology of the title itself, seemed to treat that aspect of the subject which was of particular interest to him. Besides the statement of content revealed in the title, (Continued on page 217) 
least to discount the importance of a librarian's being a subject matter specialist; it simply tries to draw attention to the fact that few librarians are subject specialists and even if they are that does not indicate a knowledge on their part of the bibliographic sources and literature of their fields. Then it seems reasonable, perfectly possible, and earnestly desirable for such a staff group-study plan to be developed in college and university libraries.

Librarians should cease proclaiming that library schools are to blame for this lack of special subject knowledge on the part of the school graduates. The schools have to admit the best of the applicants who seek entrance. If the science, social science, and art majors are not attracted to librarian- ship, who is to blame? The schools cannot supply training in these subjects, even if their faculties were equipped to do so. The only alternative, as Dean Reece suggests, is to get this knowledge either in college or after the library course. College and university librarians have a double responsibility in the matter: (I) to recruit more students with a greater variety of subject majors, (2) to develop sound in-service group-study programs to fill in this gap. The sooner, then, that librarians stop making the library schools their scapegoat and get down to business in fulfilling their own responsibilities, the more quickly will library staffs improve their educational foundation to meet the scholarly demands of college and university educational goals.

\section{The Graduate Student's Use of the Subject Catalog}

\section{(Continued from page 208)}

the student relied on the contents notes and any other bibliographical notes which furnished a clue to contents. The Library of Congress suggestions for subject headings were taken for contents notes by many of the students and were customarily considered in making selections of titles.

While the subject content of a book was the most important single consideration when the student was deciding which of the English titles he would select, those students who were familiar with their subjects or who had consulted bibliographies before coming to the catalog frequently chose certain titles because they recognized the author's name.

On the other hand, there were few who indicated that the date of the book influenced their choice. Some of those who did state a preference for recent books were studying subjects where the only material available had been published recently.
In summary, it can be said that the nature of the topic which the student was studying and the design of the catalog itself contributed to the dissatisfaction he experienced in using the subject catalog. The topical character of the subjects plus the fact that they frequently dealt with a limited area of a relatively undeveloped field made the periodical indexes a more fruitful source of references than the subject catalog.

Furthermore, the students, in trying to locate material through the subject catalog, were handicapped because they did not know precisely what it was the catalog was equipped to do nor the kind of material which could reasonably be expected to be listed in the subject catalog. Moreover, lacking experience and skill in the use of the catalog, they were not always able to find information which was readily available to them through the subject catalog. 